\title{
Introduction
}

\section{Colin Robinson}

A series of lectures on regulatory issues is held in the autumn of each year, organized by the London Business School and the Institute of Economic Affairs and named the 'Beesley Lectures' after the late Professor Michael Beesley who originated the series in 1991. The twelfth series of lectures, in the autumn of 2002, again attracted distinguished speakers and chairmen: the chairman of each lecture also acts as discussant, commenting on the paper after it is given. Both the lectures and the chairmen's comments, revised by the speakers, are reprinted in this volume.

Since the series began, a huge amount of experience has accumulated regarding how and how not to regulate privatized industries. In the early days, lecturers would usually speak in broad terms about how regulation was developing in one of the British regulated utilities. Now, however, the issues have become more specific; some of them cross the boundaries of particular industries, and international experience of regulation is a significant element in the series.

One of Michael Beesley's aims in establishing these lectures was to provide a forum in which utility regulation could be discussed, in which best practice could be established and in which the regulators themselves, as well as academic and other commentators, could have their say. He was concerned also that regulation should have a liberal inclination, promoting competition wherever possible. His aims have largely been fulfilled. The annual volumes in which the lectures are reprinted are an important historical record of how both regulators and expert observers of regulation, from Britain and overseas, have seen the practice of utility regulation evolve over the years. Moreover, they reflect the tensions which exist between deregulation, the introduction of competition and the tendency to reregulate.

The papers in this volume begin with a chapter by J. Gregory Sidak, of the American Enterprise Institute, in which he takes a critical look at deregulation of telecommunications in the United States. He argues that deregulation has increased regulation, with considerable administrative costs. Moving from regulation to a 'truly deregulated market is costly, and the alternative of managed competition is surely costlier'. It would have been better to have applied a consumer-welfare, rather than competitor-welfare, standard. Sidak also contends that the Federal Communications Commission was a at faults over ${ }^{\circ}$ Worleterop: 
the FCC was 'oblivious to the largest accounting fraud in history'. Regulators 'should not interfere if WorldCom soon ceases to exist'.

David Edmonds, Britain's Director-General of Telecommunications, agrees with Sidak that regulation should be about promoting the consumer interest, but argues that, in a market such as Britain's with a powerful incumbent, regulation will often have to be intrusive as the market evolves towards competition. $\mathrm{He}$ is more cautious than Sidak about dealing with company failures. It is difficult, says Edmonds, not to become involved if there is the possibility of some consumers suffering loss of supply.

Chapter 2 is by David Starkie of Economics-Plus Limited who examines roads from a network point of view. He emphasizes the importance of introducing a market approach into road services 'by integrating pricing and investment decisions and by offering road users a choice of different road services at different prices'. Starkie says that, at the margin, the unit costs of widening motorways are increasing and it would not be efficient to proceed with a number of such schemes. Capacity might be better used if the length of time taken by road works could be curtailed and if speed differentials could be reduced. He would also like to see the price mechanism integrated into the design of new road schemes. An economic regulator for roads could promote efficient pricing and provision of road services.

Leonard Waverman of London Business School discusses David Starkie's paper and asks, what is the optimal level of congestion? On the demand side, the value of time is crucial. If, for example, time savings were ignored except for business trips, there would be few additions to the roads network. Leisure time should be included, argues Waverman, because it has an opportunity cost, though including all leisure time lost, valued at the wage, would probably produce too many highways. He is sceptical of the idea of speed governors to reduce speed differentials.

In Chapter 3, George Yarrow of the Regulatory Policy Institute, Oxford, assesses the Enterprise Bill, which he thinks, on balance, 'represents continued, albeit limited, progress towards a more well designed competition policy'. In particular, he approves of the underlying approach of avoiding detailed political supervision. His reservations concern the reluctance he perceives to permit judicial supervision of the substance of enforcement decisions, the failure to address aspects of public policy that hinder competition (such as environmental and health and safety regulation), and the lack of coherence in Britain's framework of competition policy which now incorporates some elements of the US and EU systems.

Sir Derek Morris, Chairman of the Competition Commission, commenting on George Yarrow's critique, is not persuaded that the Bill raises real procedural problems. Nor does he agree that the Competition Commission's role is primarily regulatory. He agrees that Britain has incorporated elements of other2systems 
into its new competition legislation but 'Absorbing what appears to be the best of the rest is probably not an unsound benchmark for action in any walk of life.' Britain's new legislation should, for example, provide a 'more robust merger regime than in Europe' without the very time-consuming procedures of the United States.

Martin Cave, of Warwick University, considers in Chapter 4 the extent to which Ofcom can apply 'light touch' regulation, as it is enjoined to do by the 2002 Communications Bill, to the telecommunications, pay-TV and public service broadcasting markets. He discusses also the arrangements for the allocation of spectrum. He expects deregulation of BT's retail activities but 'ex ante regulatory oversight of some of its network or wholesale activities ... in the medium term'. BSkyB's market power will be dealt with through competition law. The BBC's advantageous position, because of the licence fee, means that regulation will be required to ensure it does not distort competition when it goes beyond its public service broadcasting remit. Ofcom should, he thinks, be looking at and, if necessary, implementing innovatory ideas about the allocation of spectrum.

Irwin Stelzer, of Irwin M. Stelzer Associates, remarks on the absence of clear regulatory procedures in Britain. He is even more concerned than Martin Cave about the difficulty of regulating vertically integrated companies with market power at one horizontal level and suggests that vertical disintegration may be required. Similarly, as regards the $\mathrm{BBC}$, he sees great difficulty in drawing the boundary between public service and commercial activities: 'really rigid vertical separation' may be necessary. Stelzer maintains also that there is more overlap between the BBC and BSkyB than is generally recognized, thus complicating the regulator's task.

The fifth chapter, by Christopher Nash of the University of Leeds, discusses the future of the railways. He stresses the differences between the railways and other network industries which were, he contends, not sufficiently recognized at the time of privatization and which have led to some of the many problems that have been encountered. Economic analysis can be helpful in dealing with these but there are major political difficulties in implementing the necessary changes. Independent regulation is still required, in his view, though solutions to many of the problems will have to be sought by the Strategic Rail Authority. The most important area where progress is required is providing adequate incentives to train operating companies 'to develop their services in the most socially desirable way, and to make the most efficient use of track capacity'.

Tom Winsor, the rail regulator, comments on each of the issues raised by Nash. On timetabling and capacity use he argues that the decision criteria applied by his office are simpler and give more predictable results than Nash suggests. As regards cost increases, Winsor argues that Railtrack is too ready to accept increases claimed by the Train Operating Conpantres: Now 
an 'engaged and competent' Strategic Rail Authority (SRA), he expects better and faster decisions about capacity utilization: he criticizes Railtrack for its failure to produce a long-term strategy, thus making invention of the SRA necessary. He agrees with Nash about the need for 'strong accountability between infrastructure user and infrastructure provider'.

Chapter 6, by Frits Bolkestein, the European Union's Internal Market Commissioner, points out that the internal market is by no means complete. As part of its completion, the aim is to liberalize large parts of European utility markets. Energy liberalization is under way, though 'two big players, Germany and France, lag behind'. There are, says Bolkestein, fears that energy liberalization will cause similar problems to those in California in 2000. However the European situation is fundamentally different and, in any case, California's problems were not the result of liberalization. Bolkestein argues that increased use of nuclear power would increase diversification of energy sources and help meet Kyoto commitments. He also examines the prospects for liberalization of water markets, arguing that 'steps towards market opening of the water sector are feasible'.

Commenting on Bolkestein's paper, Philip Fletcher, the water regulator for England and Wales, concentrates his remarks on water. He points to some of the problems in liberalizing water markets, arguing that, in the nineteenth century, when London had a free market in water in its 'rudest and rawest form', malpractices and health problems abounded. Privatization of water without liberalization has, however, brought major benefits in terms of improved quality of drinking water and river water in England and Wales. A massive investment programme underlies these improvements. The British government wants more competition for business users but is unwilling to move to full competition in the domestic sector.

Postal regulation is the subject of Chapter 7, by Ian Senior, of the consultancy, Triangle Management Services. The Postal Services Act 2000 is, in his view, on the right lines in aiming for liberalization but it is flawed by attempts at social engineering. The main part of his paper proposes a set of criteria by which to judge good postal regulation. In particular, postal regulators should be independent of government, they should issue licences freely, they should not intervene on service quality, they should set access charges to former incumbents' 'final mile' networks, they should intervene to prevent predatory pricing, a clear date for full market liberalization should be set and, once that date is reached, they should phase out their roles as 'specialist regulator and watchdog'. Senior assesses Postcomm against these criteria and finds some 'passes' and some 'serious failures'.

Graham Corbett, Chairman of Postcomm, agrees that postal regulation should have the 'shortest life practicable' but takes issue with Senior's assessment of Postcomm's performance so far. The criticism thati Postecomm faitleet 
a liberal licensing policy is inappropriate, says Corbett, because Postcomm first had to carry out an investigation to ensure there would be no material damage to the universal service. Nor could Postcomm have avoided intervention on service standards because competition might have taken too long to produce standards that were acceptable. Finally oversight of Royal Mail prices is also justifiable so long as Royal Mail remains the dominant player in the market.

In Chapter 8, Doug Andrew, of the Civil Aviation Authority (at the time he gave the lecture), examines the aviation industry as an example of the problems of providing incentives for investment in a regulated industry, considering the effects of both market failure and government failure. He points out the substantial benefits to consumers that have arisen through aviation market liberalization and argues that further benefits could be achieved through more liberalization. The 'commercial model has worked well in aviation,' he concludes. Public policy problems now lie principally in upstream infrastructure markets where excess demand is a significant issue in parts of the UK: lessons from the downstream markets about the advantages of the commercial approach are only slowly being learned.

Andrew Sentance, of British Airways, agrees that commercial models are the right way forward, but, he says, the market will not solve all problems: in particular, the airline industry is plagued by periodic overcapacity. Sentance argues that Doug Andrew is 'trying to promote a form of deregulation without a significant injection of competition' which will create problems for airlines. He is concerned about the CAA's proposal to substitute a 'dual till' for the present 'single till' because it is complex and is likely to increase prices. He wants stability in the regulatory structure. He also emphasizes the need for a clearer airport strategy, effective action on environmental issues and a streamlined planning system.

Colin Robinson, in the last chapter, argues that the government has not learned the lessons of history, in particular the disadvantages of a centralized, prescriptive energy policy which in the past has produced unintended and unwelcome results. The proposals made by the government's Performance and Innovation Unit, despite their emphasis on the benefits of liberalized markets, are, he says, in practice a recipe for significant old-style intervention in energy markets. There may be reasons to intervene on environmental grounds but it would be better done by general instruments, such as a carbon tax, rather than 'the mix of interventionist ideas in the PIU report'. He claims also that the PIU approach runs the risk of encroaching on the system of independent regulation of the gas and electricity industries which has produced such good results.

Callum McCarthy, Chairman of the Gas and Electricity Markets Authority, accepts that the 'frailties of planning' should be avoided and draws attention to the dangers of 'gapology'. He is less certain, however, of Robinson's rejection of government planning. He argues that, rather than reject it entirely, owe shlourld 
think about ways in which intervention might successfully be achieved. He agrees that general rather than specific measures are preferable and would like to see any such measures as comprehensive as possible. Government will always be under pressure to act, he says, and it is important to develop guidance to make any actions as productive as possible.

The host of issues examined in this volume illustrate the changing nature of utility regulation in Britain and overseas as, where markets are in place, they evolve and as, where regulators still attempt to control, they battle with new and complex issues. The respective roles of governments and regulators are still not clearly defined (and may never be), and so the future of 'independent' regulation is not plain. Regulators' roles now differ markedly as between the different privatized utilities in Britain. Some, such as water and the railways, are little touched by liberalization and are primarily under the supervision of a regulator, whereas in the energy utilities there are now well established competitive markets and most price controls have been removed, leaving relatively 'lighttouch' regulation. Another issue is whether in Britain, in the medium to long term, regulation will remain primarily of the 'home-grown' variety or whether it will conform to an EU-harmonized norm. It is this constantly changing scene that will be under discussion in future series of Beesley Lectures. 